\title{
Confirmatory Defect Analyses of AGR-5/6/7 Fuel
}

Douglas W. Marshall

The INL is a

U.S. Department of Energy

National Laboratory

operated by

Battelle Energy Alliance

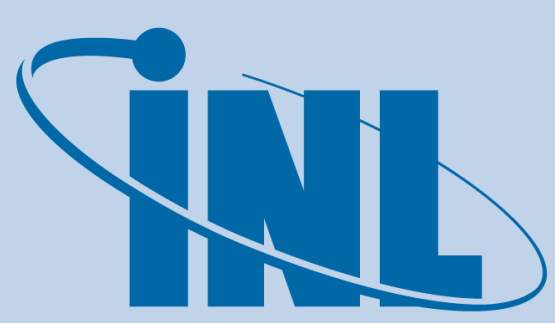

Idaho National Laboratory
April 2018

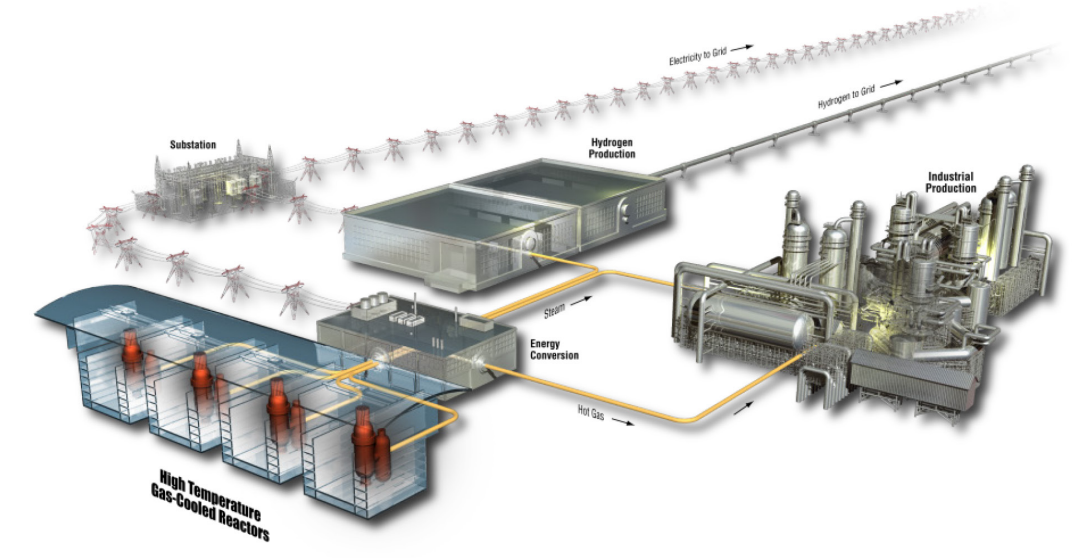




\section{DISCLAIMER}

This information was prepared as an account of work sponsored by an agency of the U.S. Government. Neither the U.S. Government nor any agency thereof, nor any of their employees, makes any warranty, expressed or implied, or assumes any legal liability or responsibility for the accuracy, completeness, or usefulness, of any information, apparatus, product, or process disclosed, or represents that its use would not infringe privately owned rights. References herein to any specific commercial product, process, or service by trade name, trade mark, manufacturer, or otherwise, does not necessarily constitute or imply its endorsement, recommendation, or favoring by the U.S. Government or any agency thereof. The views and opinions of authors expressed herein do not necessarily state or reflect those of the U.S. Government or any agency thereof. 


\title{
Confirmatory Defect Analyses of AGR-5/6/7 Fuel
}

\author{
Douglas W. Marshall
}

April 2018

\begin{abstract}
Idaho National Laboratory ART Program

Idaho Falls, Idaho 83415
\end{abstract}

http://www.inl.gov

Prepared for the

U.S. Department of Energy

Office of Nuclear Energy

Under DOE Idaho Operations Office

Contract DE-AC07-05ID14517 


\title{
ART Program \\ Confirmatory Defect Analyses of AGR-5/6/7 Fuel
}

\author{
INL/EXT--18-45110 \\ Revision 0
}

April 2018

Author:
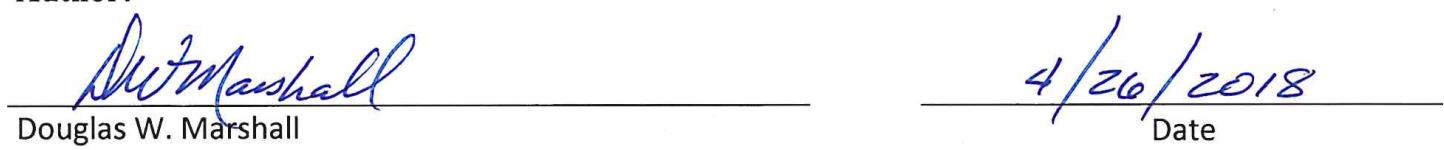

ART Fuel Fabrication Technical Lead

Technical Reviewer:
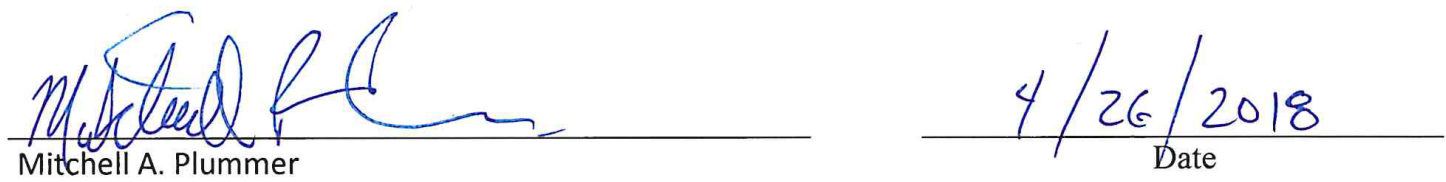

NDMAS Technical Lead

Approved by:
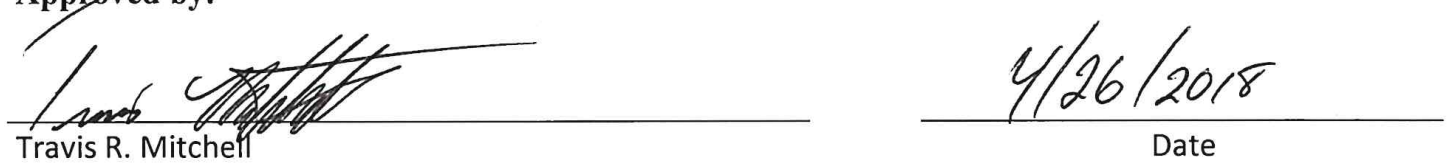

Program Manager

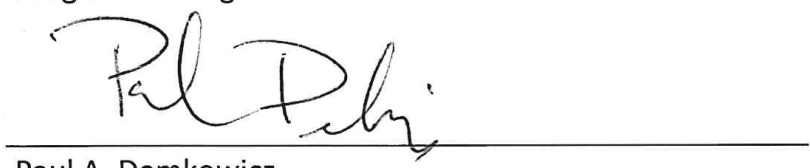

Paul A. Demkowicz

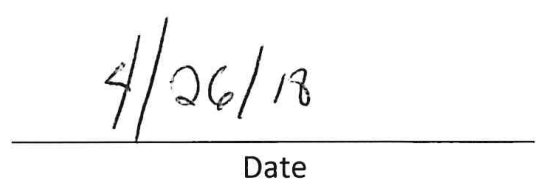

AGR Fuels Director

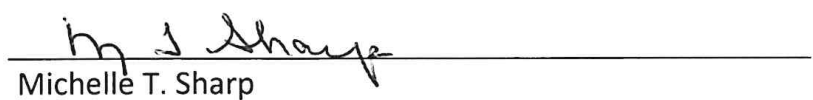

$\frac{4 / 26 / 2018}{\text { Date }}$

INL Quality Engineer 


\section{ABSTRACT}

The Advanced Gas Reactor (AGR) Fuel Development and Qualification Program has executed a series of experiments to test and qualify tristructural isotropic (TRISO) particle fuels for use in hightemperature gas-cooled reactors. The most recent irradiation experiments, AGR-5/6/7, are testing fuel that was fabricated in near production-scale equipment.

There are three important defect fractions that must be characterized, using a deconsolidation-leach-burn-leach (DLBL) method, to better predict and understand fuel performance during irradiation. These are the dispersed uranium fraction (DUF), exposed kernel fraction (EKF), and silicon carbide defect fraction (SDF).

The DLBL characterization data from analyses of the four compact batches, fabricated and characterized by the BWX Technologies Nuclear Operations Group (BWXT-NOG), showed unexpectedly higher values for all three defect fractions relative to the parent TRISO particle defect fractions. The DUF and SDF should not have changed significantly during compact fabrication and the apparent increase in the EKF, a metric for particle damage, was higher than anticipated for the compacts with $40 \%$ volumetric packing fraction (PF). Analytical results showed no net increase in the EKF for the $25 \%$ PF compacts. Compacts from one compact batch of each packing fraction were sent to Oak Ridge National Laboratory (ORNL), along with uncompacted tristructural isotropic (TRISO) particles, overcoated to a thickness targeting a $40 \% \mathrm{PF}$, for confirmatory analyses of the defect fractions and determination of the source(s) of damage.

The ORNL results did not confirm the BWXT-NOG results for either the DUF or the SDF; the ORNL results showed no significant change in these defect fractions relative to the parent TRISO particle lot. The ORNL results did, however, confirm that a large increase in the exposed kernel fraction was found in the $40 \%$ PF compacts and that the $25 \%$ PF compacts sustained little if any damage. Data suggest that a large majority of the mechanical damage to the TRISO particles occurred in the overcoater when targeting the $40 \% \mathrm{PF}$.

The analytical laboratories at both BWXT-NOG and ORNL had inconsistent outcomes on analyses of individual batches. Although the ORNL data is more consistent with the parent TRISO lot and expectations, the data set is too limited in size to justifiably reject suspect data from either laboratory at this time. It is recommended that an additional analysis be done to provide sufficient data for estimating the true defect fractions for interpreting the radionuclide release data during the AGR-5/6/7 irradiation experiments. 


\section{CONTENTS}

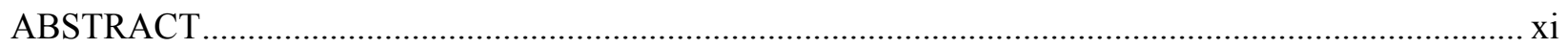

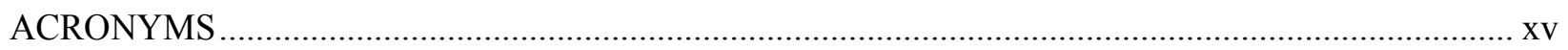

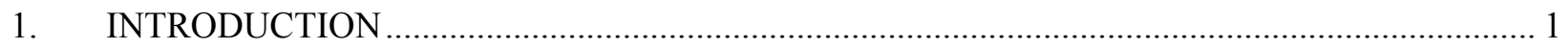

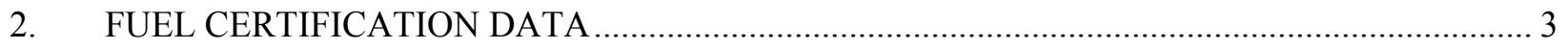

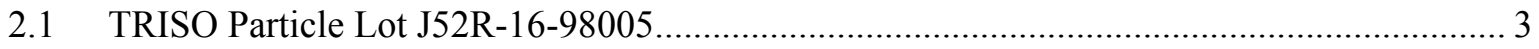

2.2 Overcoated TRISO Particle Batch J52R-16-11034 _......................................................... 3

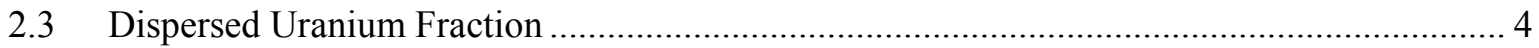

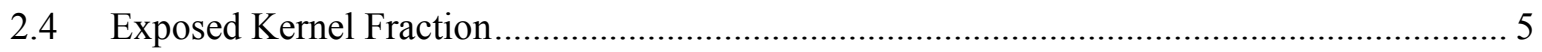

2.5 Silicon Carbide Defect Fraction .......................................................................................... 7

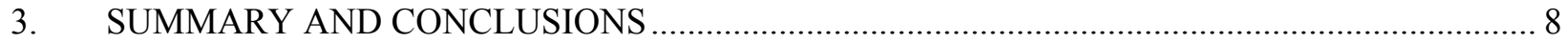

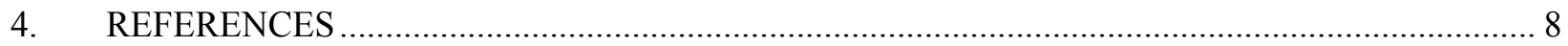

\section{FIGURES}

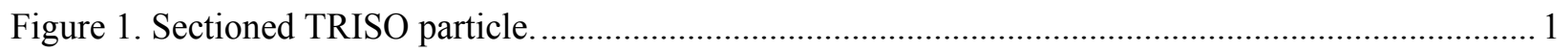

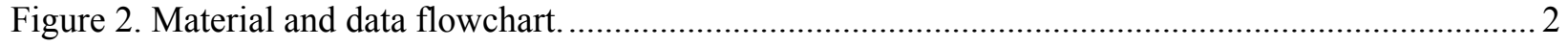

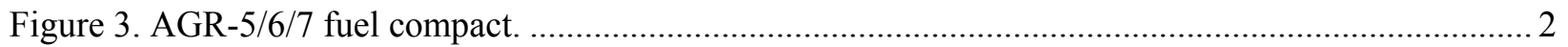

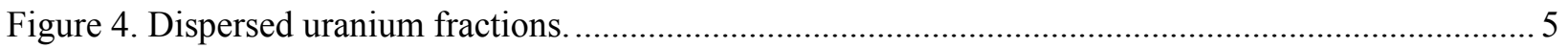

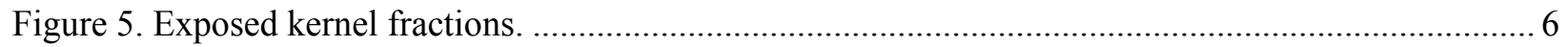

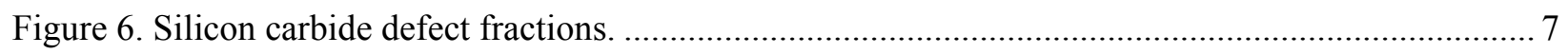

\section{TABLES}

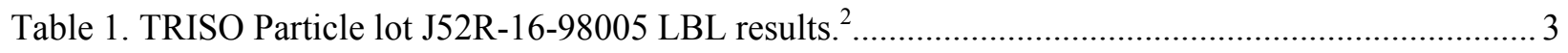

Table 2. Overcoated TRISO batch J52R-16-11034 (40\% PF) LBL results. ${ }^{1}$.............................................. 4

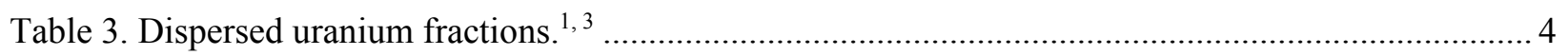

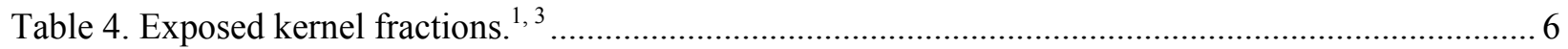

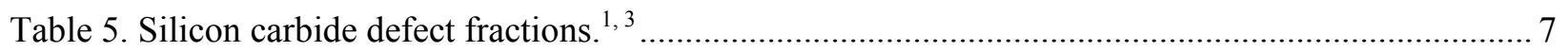




\section{ACRONYMS}

$\begin{array}{ll}\text { BWXT-NOG } & \text { BWX Technologies Nuclear Operations Group } \\ \text { DLBL } & \begin{array}{l}\text { deconsolidation leach-burn-leach } \\ \text { dispersed uranium fraction } \\ \text { DUF }\end{array} \\ \text { EKF } & \text { exposed kernel fraction } \\ \text { IPyC } & \text { inner pyrocarbon } \\ \text { KPA } & \text { kinetic phosphorescence analysis } \\ \text { LBL } & \text { leach-burn-leach } \\ \text { OPyC } & \text { outer pyrocarbon } \\ \text { ORNL } & \text { Oak Ridge National Laboratory } \\ \text { PF } & \text { volumetric packing fraction } \\ \text { SDF } & \text { silicon carbide defect fraction } \\ \text { SiC } & \text { silicon carbide } \\ \text { TRISO } & \text { tristructural isotropic }\end{array}$




\section{Confirmatory Defect Analyses of AGR-5/6/7 Fuel \\ 1. INTRODUCTION}

The Advanced Gas Reactor Fuel Development and Qualification Program has executed a series of irradiation experiments to test and qualify tristructural isotropic (TRISO) particle fuels, in a graphitic matrix fuel form, for use in high-temperature gas-cooled reactors. The most recent irradiation experiments, AGR-5/6/7, are intended to test fuel that was fabricated in near production-scale equipment and to provide data for normal operations as well as a reactor parameter "margin" test.

TRISO particle fuels rely on four coating layers to contain the majority of fission products during and after irradiation. The first layer (Figure 1, A) is a low-density carbon "buffer" coating on the fuel kernel that provides space for fission gas accumulation and absorbs the kinetic energy of ejected fission fragments. The second layer (Figure 1, B) is a dense inner pyrocarbon (IPyC) layer that seals the particles from gas releases and prevents corrosive fission products from attacking the third layer (Figure 1, C) made of silicon carbide. The silicon carbide layer is the structural backbone of the TRISO particle and a barrier against fission product migration. The outer layer (Figure 1, D) is another dense pyrocarbon layer $(\mathrm{OPyC})$ that protects the silicon carbide from mechanical damage during handling and is the final barrier to fission product release.

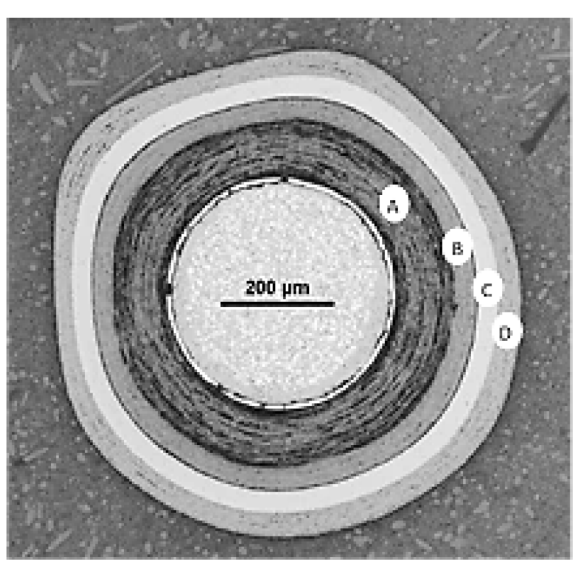

Figure 1. Sectioned TRISO particle.

The TRISO particle lot J52R-16-98005 was selected as the parent material for all fuel compacts fabricated for the AGR-5/6/7 irradiation experiments (Figure 2) at the BWX Technologies Nuclear Operations Group (BWXT-NOG) facilities in Lynchburg, Virginia. Four aliquots of the TRISO particle lot were individually overcoated with a resinated graphite "matrix" powder, targeting a nominal TRISO particle volumetric packing fraction (PF) of either $25 \%$ or $40 \%$. Each overcoated TRISO particle batch was pressed into cylindrical fuel compacts, $1 / 2$ " diameter, 1 " long (Figure 3). For the AGR-5/6/7 irradiation experiment, the 40\% PF compacts occupy the two end capsules and the $25 \%$ PF compacts occupy the three middle capsules of the test train.

After compaction, the compacts are heated to carbonize the resin, devolatilize the matrix, and improve the matrix thermal conductivity. Four furnace runs were conducted, which were designated as A through D. Compacts from each batch included in the four furnace runs, with the furnace run designator being appended to the compact batch identifier (e.g., J52R-16-14154A). 


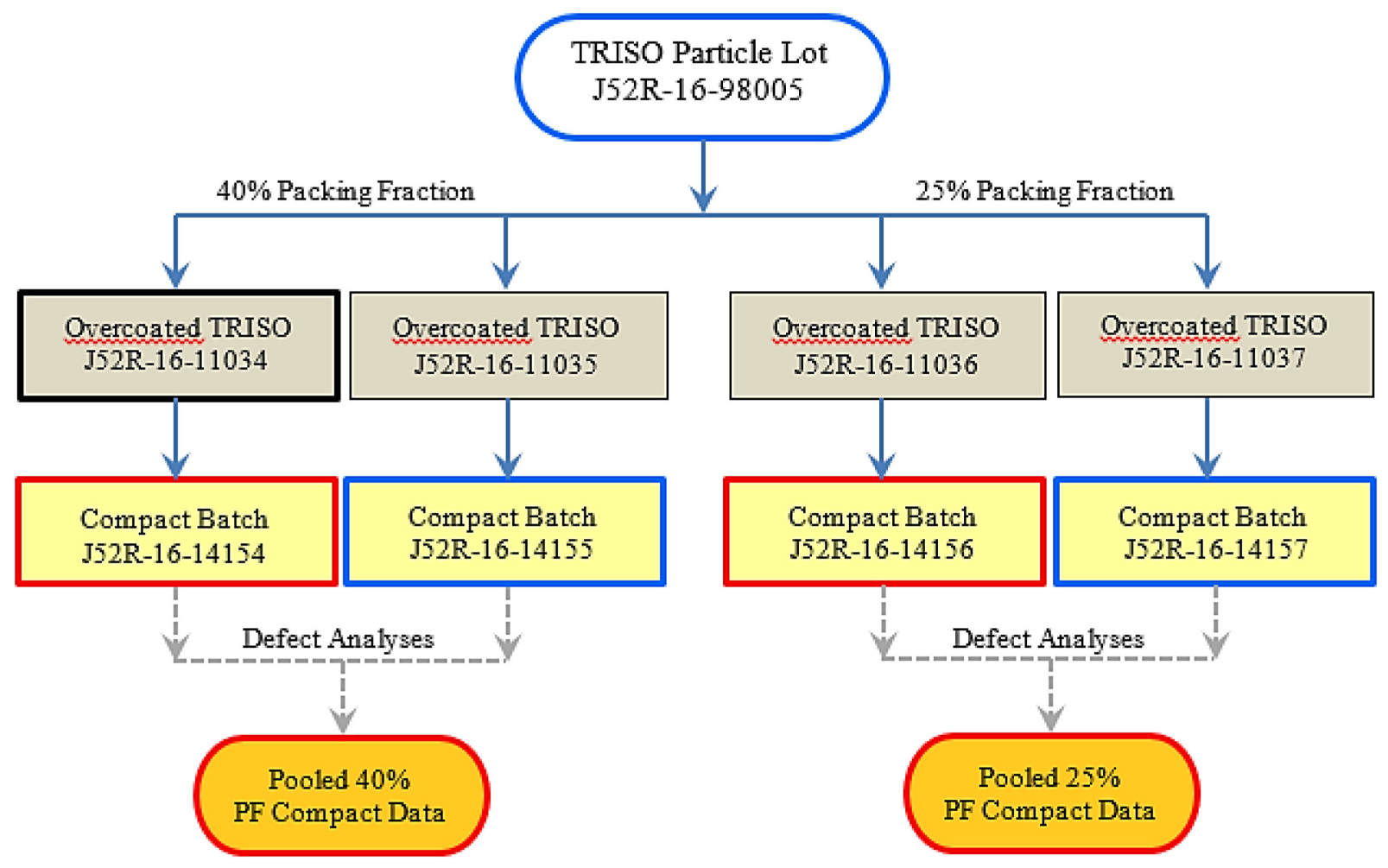

Bold BLUE border $\rightarrow$ BWXT-NOG data only

Bold BLACK border $\rightarrow$ ORNL data only

Bold RED border $\rightarrow$ BWXT-NOG \& ORNL data

Figure 2. Material and data flowchart.

There are three important fuel defect fractions that must be characterized, using a deconsolidation-leach-burn-leach (DLBL) method developed by Oak Ridge National Laboratory (ORNL), to better predict and understand fuel performance during irradiation. These are the dispersed uranium fraction (DUF), exposed kernel fraction (EKF), and silicon carbide (SiC) defect fraction (SDF). The DUF is a metric for trace

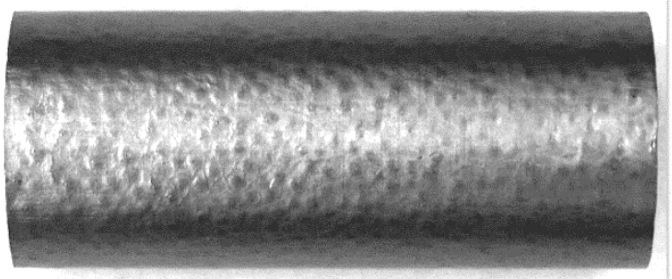

Figure 3. AGR-5/6/7 fuel compact. quantities of uranium contamination that are trapped in the outermost pyrocarbon layer of the TRISO particle and matrix relative to the uranium in the compact. The EKF is a metric for physically damaged particles with cracked or broken coating layers relative to the total particle count in the compact. The SDF is a metric for number of particles with connected porosity in the silicon carbide layer relative to the total particle count in the compact.

In the DLBL method, a "clutch" of five fuel compacts are electrolytically deconsolidated in nitric acid to liberate the TRISO particles from the graphitic matrix. Some of the dispersed uranium and all of the uranium from exposed kernels are dissolved during deconsolidation and subsequent series of acid leaches. Clutches with less leached uranium than a half kernel equivalent are assumed to exhibit only dispersed uranium. Those with leached uranium near integer kernel equivalents likely represent exposed kernels. 
Following the leaches, the OPyC layer is "burned back" by oxidation in a furnace. This exposes the remaining dispersed uranium and, if the silicon carbide layer is porous, oxidizes the IPyC and buffer layers to expose the uranium kernel to attack by a final set of acid leaches. Again, those clutches with less leached uranium than a half kernel equivalent exhibit only dispersed uranium while those with near integer kernel equivalents reveal silicon carbide defects.

The TRISO particle lot was analyzed with a modified leach-burn-leach (LBL) method, which showed that the DUF was marginally above the compact specification, but that the EKF and SDF were well below the specifications by a factor of five. The TRISO particle lot was deemed suitable for fuel fabrication.

DLBL analyses of the compacts fabricated for the irradiation campaign, analyzed by the BWXT-NOG, exhibited higher values for all three defect fractions than measured in the parent TRISO particle lot and the data showed some inconsistent outcomes that call the integrity of the data into question. Samples of compacts and TRISO particles, which had been overcoated with resinated graphite powder, were sent to ORNL for confirmatory analysis and to provide a better understanding of the source of TRISO particle damage (overcoater versus compacting press). ${ }^{1}$

\section{FUEL CERTIFICATION DATA}

\subsection{TRISO Particle Lot J52R-16-98005}

BWXT-NOG submitted fuel characterization and certification packages to Battelle Energy Alliance, LLC, for TRISO particle lot J52R-16-98005 ${ }^{2}$ and for the AGR-5/6/7 fuel compacts. ${ }^{3}$ The TRISO particle lot was characterized by LBL for information only, since there is no fuel specification for the TRISO particles relating to the DUF, EKF, or SDF, and to provide some assurance that the fuel compacts would be capable of meeting fuel compact specifications. ${ }^{4}$

The TRISO particle sample was divided into six aliquots of 53,000 to 54,000 particles each. The large aliquots reduced the number of concurrent analyses in progress in the laboratory, but also impaired the statistics. The aliquots were roughly equivalent to 15 to 23 fuel compacts, whereas a typical "clutch" of compacts subjected to DLBL is five. These six aliquots (totaling $\sim 319,000$ particles) were analyzed prior to the burn-back to provide an adequate population for the EKF metric. Of the six aliquots, three (totaling $\sim 159,000$ particles) were burned-back to the SiC layer and leached for the SDF metric. Only one of the three aliquots in the post-burn leach set exhibited no exposed kernels, so no standard deviation for the DUF could be quantified on those aliquots. Thus, the DUF statistical confidence interval calculation was unattainable, but the reported mean defect fraction should be representative. The LBL results for the TRISO particle lot are given in Table 1 and graphically in Sections 2.3 to 2.5.

Table 1. TRISO Particle lot J52R-16-98005 LBL results. ${ }^{2}$

\begin{tabular}{|l|c|c|c|}
\hline \multicolumn{1}{|c|}{ J52R-16-98005 } & Total DUF & EKF & SDF \\
\hline Mean & $1.04 \mathrm{E}-5$ & $9.40 \mathrm{E}-6$ & $1.89 \mathrm{E}-5$ \\
\hline 95\% confidence interval & - & $\leq 2.43 \mathrm{E}-5$ & $\leq 4.88 \mathrm{E}-5$ \\
\hline
\end{tabular}

\subsection{Overcoated TRISO Particle Batch J52R-16-11034}

TRISO particles from lot J52R-16-98005 were overcoated with a resinated graphite powder, which forms the compact matrix that binds the TRISO particles together. Four overcoating batches were made in the Freund/Vector Lab 3 Granuex equipment or "overcoater." Two batches were made with a thin overcoat to yield a compact with a nominal $40 \% \mathrm{PF}$ and two with a thicker overcoat to yield a nominal $25 \%$ PF. The $40 \%$ PF batches used a "bowl" rotational speed of $300 \mathrm{rpm}$ and a 2000 -g TRISO particle charge mass while the $25 \%$ PF batches used $200 \mathrm{rpm}$ and half the charge mass. Both packing fractions 
used the same powder addition rate, so the TRISO particles in the $25 \%$ PF batches accreted graphite powder at twice the rate of the $40 \% \mathrm{PF}$ batches.

As the resinated graphite overcoat builds on the TRISO particles, it achieves sufficient thickness to protect the TRISO particles from damage due to collisions with overcoater internals and other particles. Damage to the TRISO particles should manifest only as an increase in the EKF relative to the TRISO particle lot. Changes in the DUF and SDF values are not expected. The LBL results for the $40 \% \mathrm{PF}$ overcoated TRISO particle batch, J52R-16-11034, are given in Table 2 and graphically in Sections 2.3 to 2.5 .

The DUF and SDF agree reasonably well with the TRISO particle lot values, but the EKF for the $40 \%$ PF compacts exhibits a fivefold increase in the measured mean relative to the TRISO particle lot; indicating that mechanical damage was sustained during the overcoating operation. There is little evidence to suggest that the TRISO particles in the $25 \%$ PF batches sustained damage. Whether the damage to the $40 \%$ PF fuel was sustained solely because of the higher bowl rotational speed or if the slower powder accretion rate was a contributor cannot be determined with available data.

Table 2. Overcoated TRISO batch J52R-16-11034 (40\% PF) LBL results. ${ }^{1}$

\begin{tabular}{|l|c|c|c|}
\hline \multicolumn{1}{|c|}{ J52R-16-11034 } & Total DUF & EKF & SDF \\
\hline Mean & $8.19 \mathrm{E}-6$ & $4.07 \mathrm{E}-5$ & $6.79 \mathrm{E}-6$ \\
\hline $95 \%$ confidence interval & $\leq 1.09 \mathrm{E}-5$ & $\leq 8.04 \mathrm{E}-5$ & $\leq 3.22 \mathrm{E}-5$ \\
\hline
\end{tabular}

\subsection{Dispersed Uranium Fraction}

ORNL reports that the deconsolidated compacts produce a viscous, ink-like slurry that is difficult to clarify of suspended graphite fines and a solids mass that is not easily transferred back-and-forth between centrifuge tube and the leaching flask. It is suspected that the difficult handling aspects of the analyses may have contributed to unexpectedly high results and anomalous batch-to-batch dissimilarities.

The DUF was also calculated by INL, using the BWXT data and the same statistical method used by ORNL, to ensure a common basis for comparison with ORNL results. One observes in Table 3 and Figure 4 that BWXT-NOG and ORNL DUF results disagree and are statistically dissimilar. The compact samples sent to ORNL included only one of the two compact batches for each packing fraction, whereas BWXT-NOG analyzed both sets of each packing fraction. Additional ORNL data are needed for compact batches that were not included in the confirmatory analyses (Figure 2) to increase the sample populations before any decision is made to reject suspect data.

Table 3. Dispersed uranium fractions. ${ }^{1,3}$

\begin{tabular}{|l|c|c|c|c|}
\hline \multirow{2}{*}{$\begin{array}{l}\text { Dispersed Uranium } \\
\text { Fraction }\end{array}$} & \multicolumn{2}{|c|}{ BWXT-NOG Data } & \multirow{2}{*}{ ORNL } & \multirow{2}{*}{ Pooled } \\
\cline { 2 - 3 } $\begin{array}{l}\text { Mean, 25\% PF } \\
\text { (batches) }\end{array}$ & $\begin{array}{c}2.66 \mathrm{E}-5 \\
(14156 \mathrm{C} \& \\
14157 \mathrm{C})\end{array}$ & $1.87 \mathrm{E}-5$ & $\begin{array}{c}8.94 \mathrm{E}-6 \\
(14156 \mathrm{C} \& \mathrm{D})\end{array}$ & $1.59 \mathrm{E}-5$ \\
\hline $95 \%$ Conf. Interval & $\leq 2.95 \mathrm{E}-5$ & $\leq 2.41 \mathrm{E}-5$ & $\leq 1.45 \mathrm{E}-5$ & $\leq 1.99 \mathrm{E}-5$ \\
\hline \hline $\begin{array}{l}\text { Mean, 40\% PF } \\
\text { (batches) }\end{array}$ & $\begin{array}{c}3.18 \mathrm{E}-5 \\
(14154 \mathrm{C} \& \\
14155 \mathrm{C})\end{array}$ & $2.41 \mathrm{E}-5$ & $\begin{array}{c}4.88 \mathrm{E}-6 \\
(14154 \mathrm{C})\end{array}$ & $1.55 \mathrm{E}-5$ \\
\hline $95 \%$ Conf. Interval & $\leq 3.80 \mathrm{E}-5$ & $\leq 7.26 \mathrm{E}-5$ & $\leq 6.88 \mathrm{E}-6$ & $\leq 2.28 \mathrm{E}-5$ \\
\hline
\end{tabular}


The ORNL results are more similar to the results from the parent TRISO particle lot and to the overcoated TRISO particle batch than are the results reported by BWXT-NOG. The ORNL results are also consistent with understanding that the DUF should be immune to mechanical damage to the TRISO shells. It is possible that the $40 \%$ PF compacts will pass the DUF specification (1.0E-5) with additional data and after suspect data are rejected, but the $25 \%$ PF compacts are unlikely to pass fuel specification within the $95 \%$ confidence interval.

The BWXT-NOG data had six clutches of 25\% PF compacts from batch J52R-16-14156C that, unexpectedly, registered zero dispersed uranium followed by six with measurable dispersed uranium or exposed kernels. This unexpected outcome for the first six clutches is likely associated with the difficult handling of the deconsolidated material or interference with the kinetic phosphorescence analysis (KPA) technique used to quantify the leached uranium at BWXT-NOG. The KPA technique registers a positive phosphorescence even with standard solutions containing no uranium, so measuring no phosphorescence is an anomaly that makes these BWXT-NOG data suspect and was an impetus behind requesting ORNL to perform confirmatory analyses.

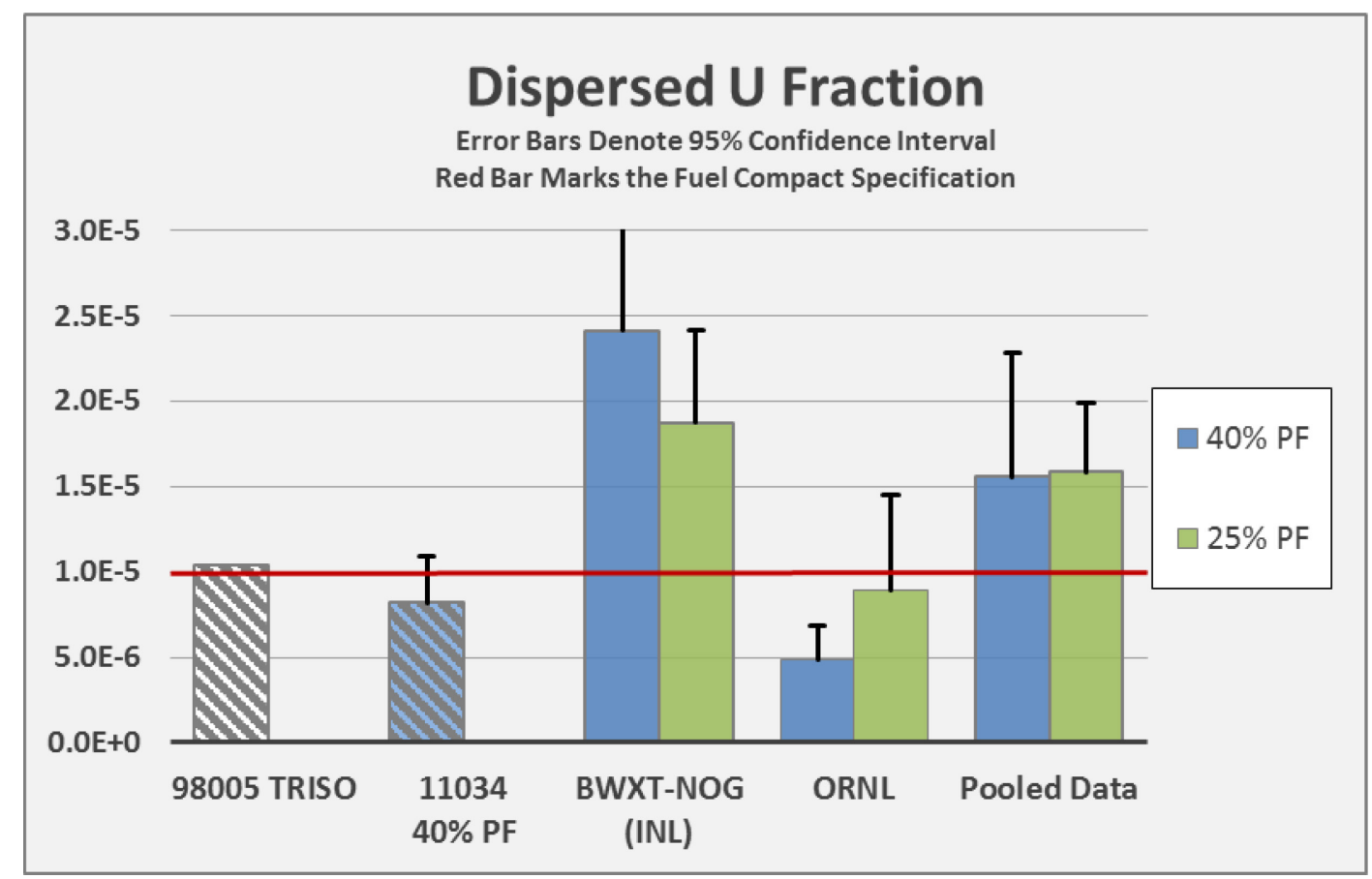

Figure 4. Dispersed uranium fractions.

Additional sampling, to include compact batches not yet tested by ORNL, would improve the statistics of the results for both packing fractions and to determine if the rejection of suspect data is warranted, which would likely result in a reduction of the pooled DUF values. No data have been rejected at this time.

\subsection{Exposed Kernel Fraction}

ORNL had a group of four clutches from J52R-16-14154C (40\% PF) that exhibited ten-times more exposed kernels than the second group of four clutches from the same batch. This is an unlikely analytical outcome and possibly associated with the difficult nature of the deconsolidated compact slurry.

The mean value for the ORNL data falls between the mean and $95 \%$ confidence interval of the BWXT-NOG data, for both packing fractions, so the data sets are largely in agreement (Table 4 and Figure 5). Additional analysis of this compact batch is needed to referee the results and to detect flawed 
data. Compacts from the second 40\% PF compact batch (14155 series) and the associated overcoated TRISO particle batch (J52R-16-11035) should also be analyzed to improve the pooled statistics and quantification of damage incurred in the overcoater. The EKF specification is a maximum of 5.0E-5 with 95\% statistical confidence.

Table 4. Exposed kernel fractions. ${ }^{1,3}$

\begin{tabular}{|l|c|c|c|c|}
\hline \multirow{2}{*}{ Exposed Kernel Fraction } & \multicolumn{2}{|c|}{ BWXT-NOG Data } & \multirow{2}{*}{ ORNL } & \multirow{2}{*}{ Pooled } \\
\cline { 2 - 3 } & Cert. Pkg & INL Calc's & \\
\hline $\begin{array}{l}\text { Mean, 25\% PF } \\
\text { (batches })\end{array}$ & $\begin{array}{c}7.39 \mathrm{E}-6 \\
(14156 \mathrm{C} \& 14157 \mathrm{C})\end{array}$ & $7.40 \mathrm{E}-6$ & $\begin{array}{c}1.09 \mathrm{E}-5 \\
(14156 \mathrm{C} \& \mathrm{D})\end{array}$ & $8.28 \mathrm{E}-6$ \\
\hline 95\% Conf. Interval & $\leq 1.48 \mathrm{E}-5$ & $\leq 2.33 \mathrm{E}-5$ & $\leq 5.18 \mathrm{E}-5$ & $\leq 2.14 \mathrm{E}-5$ \\
\hline $\begin{array}{l}\text { Mean, } \\
\text { (batches })\end{array}$ & $\begin{array}{c}6.57 \mathrm{E}-5 \\
(14154 \mathrm{C} \& 14155 \mathrm{C})\end{array}$ & $6.57 \mathrm{E}-5$ & $\begin{array}{c}7.90 \mathrm{E}-5 \\
(14154 \mathrm{C})\end{array}$ & $6.79 \mathrm{E}-5$ \\
\hline $95 \%$ Conf. Interval & $\leq 9.28 \mathrm{E}-5$ & $\leq 9.86 \mathrm{E}-5$ & $\leq 1.31 \mathrm{E}-4$ & $\leq 9.36 \mathrm{E}-5$ \\
\hline
\end{tabular}

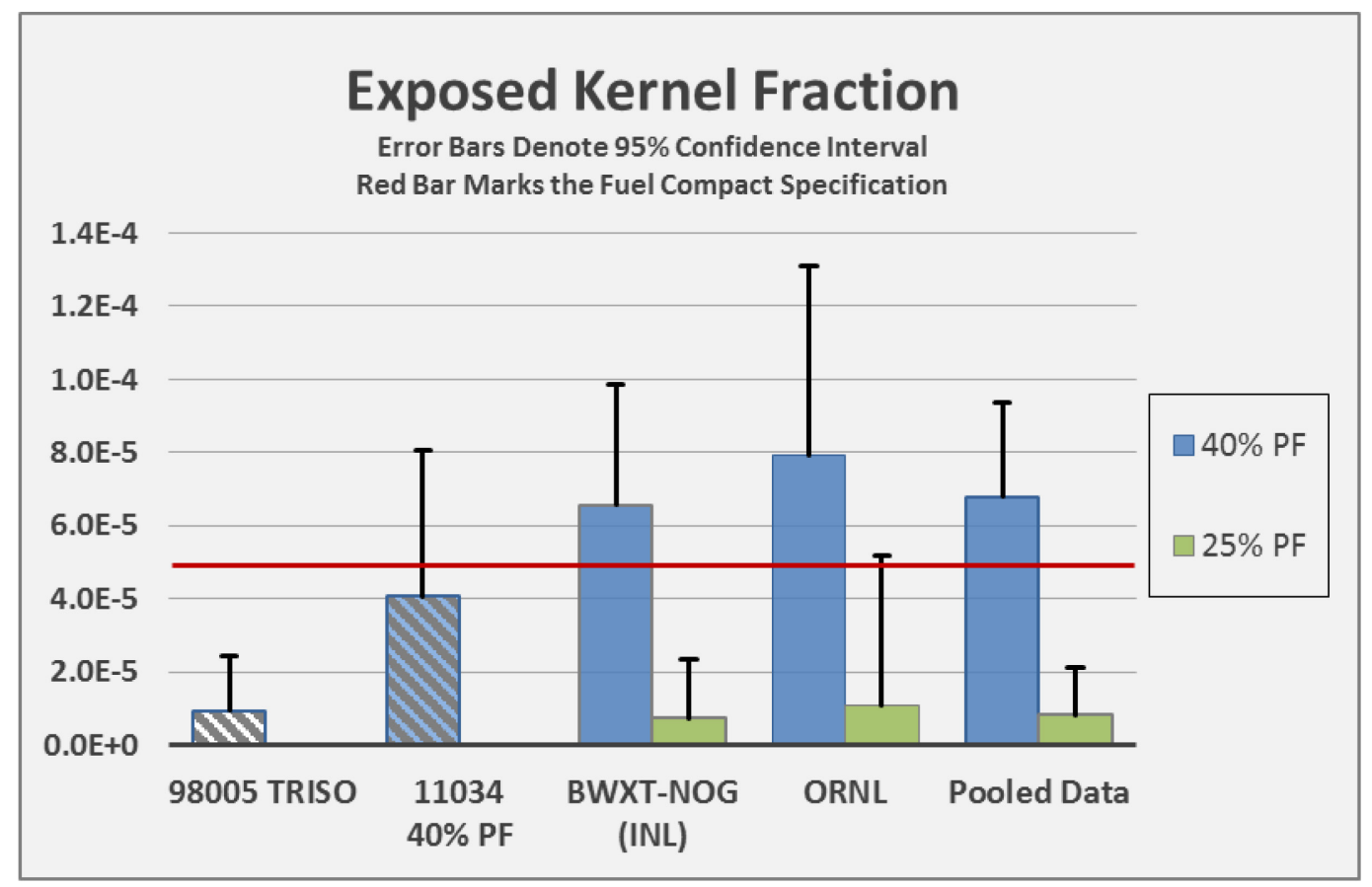

Figure 5. Exposed kernel fractions.

Data for the $25 \% \mathrm{PF}$ compacts are consistent in value with the parent TRISO particle lot and readily pass the fuel specification. The ORNL data for the $25 \%$ PF compact batch fails the fuel specification at $95 \%$ confidence only because the sample population was relatively small.

The overcoated TRISO particle batch J52R-16-11034 (40\% PF) shows a substantial increase in exposed kernel defect fraction, relative to the parent TRISO particle lot, that accounts for the majority of the sustained damage. Based on the data, about two-thirds of the damage observed in the $40 \% \mathrm{PF}$ compacts is attributable to the particle overcoating process. Additional analyses will not alter the pass/fail determination for fuel specification conformance, but they will improve the estimated mean and confidence interval for more accurate interpretation of the in-pile fuel performance data. 


\subsection{Silicon Carbide Defect Fraction}

An increase in the SDF is not expected as a result of mechanical damage to the layers. It is generally thought that the SiC layer, when it fails, will shear the adjacent pyrocarbon layers and manifest as an exposed kernel defect and not as a $\mathrm{SiC}$ defect. This would not be the case if at least one pyrocarbon layer remains intact, so a small increase in the SDF is conceivable.

The BWXT-NOG data suggest that the SiC defect did increase relative to the parent TRISO particle lot after compaction (Table 5 and Figure 6). The ORNL data, however, suggest any increase in the SDF to be minor; given that the means fall within the confidence interval of the parent TRISO particle lot and overcoated TRISO particles.

Table 5. Silicon carbide defect fractions. ${ }^{1,3}$

\begin{tabular}{|l|c|c|c|c|}
\hline \multirow{2}{*}{$\begin{array}{l}\text { Silicon Carbide Defect } \\
\text { Fraction }\end{array}$} & \multicolumn{2}{|c|}{ BWXT-NOG Data } & \multirow{2}{*}{ ORNL } & \multirow{2}{*}{ Pooled } \\
\cline { 2 - 3 } $\begin{array}{l}\text { Mean, 25\% PF } \\
\text { (batches) }\end{array}$ & $\begin{array}{c}9.24 \mathrm{E}-5 \\
(14156 \mathrm{C} \& \\
14157 \mathrm{C})\end{array}$ & $9.24 \mathrm{E}-5$ & $\begin{array}{c}3.27 \mathrm{E}-5 \\
(14156 \mathrm{C} \& \mathrm{D})\end{array}$ & $7.46 \mathrm{E}-5$ \\
\hline 95\% Conf. Interval & $\leq 1.22 \mathrm{E}-4$ & $\leq 1.29 \mathrm{E}-4$ & $\leq 8.46 \mathrm{E}-5$ & $\leq 1.03 \mathrm{E}-4$ \\
\hline $\begin{array}{l}\text { Mean, 40\% PF } \\
\text { (batches) }\end{array}$ & $\begin{array}{c}6.96 \mathrm{E}-5 \\
(14154 \mathrm{C} \& \\
14155 \mathrm{C})\end{array}$ & $6.96 \mathrm{E}-5$ & $\begin{array}{c}2.87 \mathrm{E}-5 \\
(14154 \mathrm{C})\end{array}$ & $5.53 \mathrm{E}-5$ \\
\hline $95 \%$ Conf. Interval & $\leq 9.66 \mathrm{E}-5$ & $\leq 1.03 \mathrm{E}-4$ & $\leq 6.58 \mathrm{E}-5$ & $\leq 7.90 \mathrm{E}-5$ \\
\hline
\end{tabular}

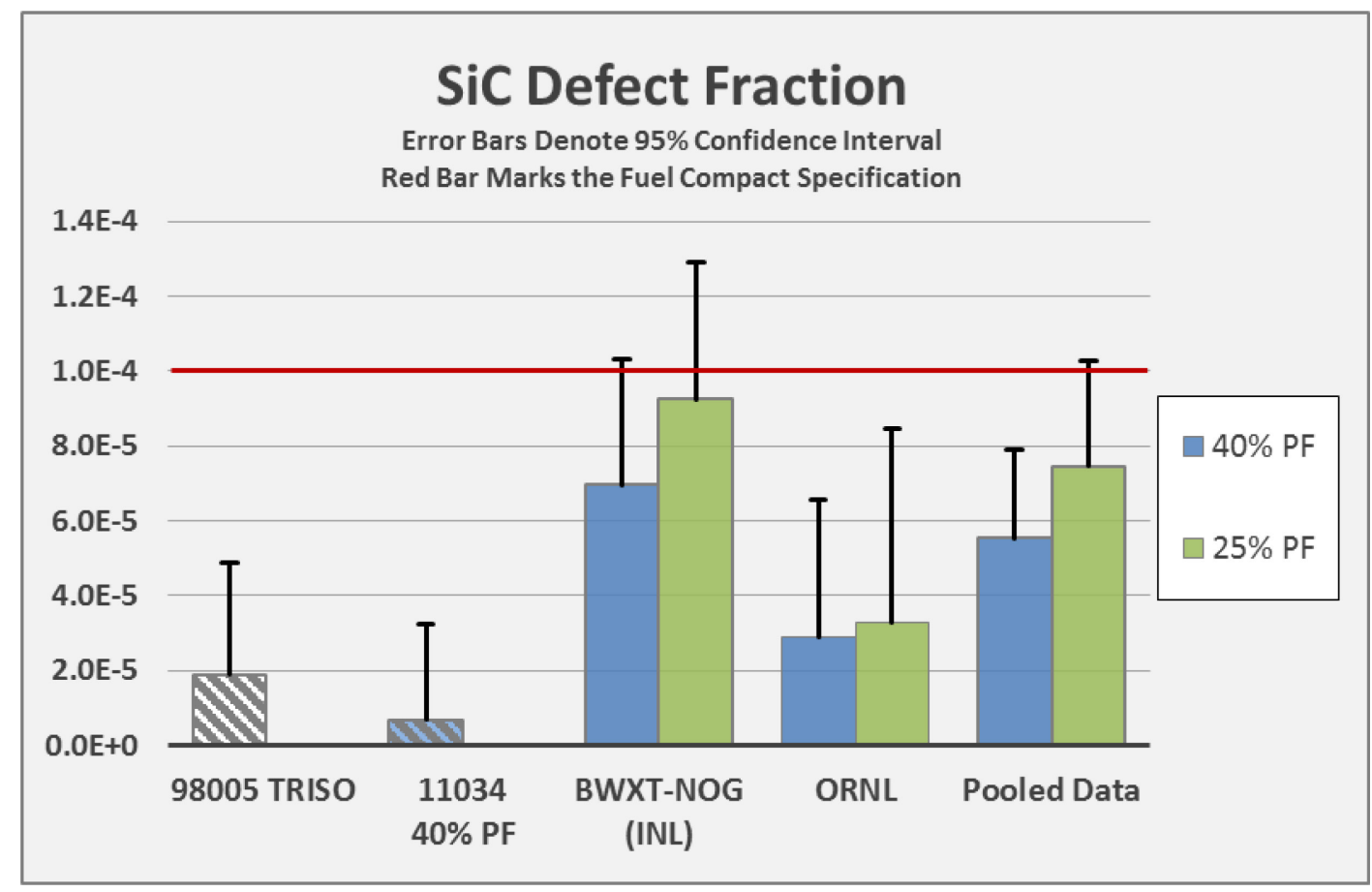

Figure 6. Silicon carbide defect fractions. 
Additional data, especially from the two unrepresented compact batches in the ORNL data, would provide improved statistics for evaluation of whether either packing fraction passes the fuel specification (1.0E-4) at 95\% confidence. Augmenting the data with LBL from the overcoated TRISO particle lot, J52R-16-11035 (40\% PF), would improve the estimate on the mean SDF of overcoated particles and facilitate a more accurate interpretation of the $40 \%$ PF compact data and a better estimate of damage incurred during particle overcoating operations.

\section{SUMMARY AND CONCLUSIONS}

The DLBL characterization results from analyses of the four compact batches, fabricated and characterized by BWXT-NOG, showed unexpected increases in all three defect fractions relative to the parent TRISO particle lot; most notably the DUF and SDF for compacts of both packing fractions, which should have remained unchanged. Analytical results also showed a large increase in the EKF for $40 \% \mathrm{PF}$ compacts, largely attributed to the overcoating process, but no net increase for the $25 \% \mathrm{PF}$ compacts relative to the parent TRISO lot. Compacts from one compact batch of each packing fraction were sent to ORNL, along with uncompacted TRISO particles, overcoated to a $40 \% \mathrm{PF}$, for confirmatory analyses of the defect fractions and determination of the source(s) of damage.

The ORNL results did not confirm the BWXT-NOG results for either the DUF or SDF, which should be unaffected by mechanical damage to TRISO particles and were consistent with analyses of the parent TRISO particle lot and overcoated TRISO particle batch. The ORNL results did, however, confirm that a large increase in the EKF was found in the $40 \%$ PF compacts and that the $25 \%$ PF compacts sustained little if any damage. Furthermore, the analysis of the overcoated, but not compacted, TRISO particles suggests that a large majority of the mechanical damage to the TRISO particles occurred in the overcoater when targeting $40 \% \mathrm{PF}$.

Because BWXT-NOG and ORNL each incurred inconsistent outcomes on individual batch analyses and because only one of each pair of compact batches was analyzed at ORNL, no suspect data from either laboratory can be justifiably rejected at this time. It is recommended that an additional 20 compacts from J52R-16-14154C (40\% PF) and 35 to 40 compacts from J52R-16-14155C (40\% PF) and J52R-16-14157C be sent to ORNL, along with about $440 \mathrm{~g}$ of uncompacted, overcoated TRISO particle batch J52R-16-11035 (40\% PF) for analysis. This should provide sufficient data to improve the estimate of the true defect fractions for use in evaluating the radionuclide release data during AGR-5/6/7 irradiation and to determine if rejection of suspect data is warranted.

\section{REFERENCES}

1. ORNL/TM-2018/774, "Confirmatory LBL Analysis of AGR-5/6/7 Compacts and Over-Coated Particles," April 2018.

2. BWXT Advanced Gas Reactor Program (AGR) Contract No. 107790, J52R, Industrial Fuel Fabrication and Development, Lot J52R-16-98005, May 2017.

3. BWXT Advanced Gas Reactor Program (AGR) Contract No. 107790, J52R, Industrial Fuel Fabrication and Development, LEU Compact Certification Package, August 2017.

4. SPC-1352, “AGR-5/6/7 Fuel Specification,” Idaho National Laboratory, Rev. 8, March 2017. 